\title{
Further Pharmacological Evidence Supporting the Development of an Antiulcerogenic Drug Based on Rhizophora mangle L. Aqueous Extract. HPLC Method Proposed for Determinating a Chemical Marker
}

\author{
Luz María Sánchez Perera1 ${ }^{*}$, Janet Piloto², Deyanira Canelsota3 ${ }^{3}$ Liliam Pelzer4, \\ Betty Mancebo ${ }^{1}$ \\ ${ }^{1}$ Departmentof Chemistry, Pharmacology and Toxicology, National Centre for Animal and Plant Health, CENSA, \\ La Habana, Cuba \\ ${ }^{2}$ Center of Medicinal Drug Development, CIDEM, Havana, Cuba \\ ${ }^{3}$ Institute National of Oncology and Radiography, INOR, Havana, Cuba \\ ${ }^{4}$ University of San Luis, San Luis, Argentina \\ Email: *luzmaria@censa.edu.cu
}

Received 23 December 2015; accepted 7 January 2016; published 11 January 2016

Copyright (C) 2016 by authors and OALib.

This work is licensed under the Creative Commons Attribution International License (CC BY). http://creativecommons.org/licenses/by/4.0/

(c) † Open Access

\begin{abstract}
Rhizophora mangle $\mathrm{L}$. is a vegetal species with high disponibility in Cuba for guarantying economical factibility by drug development. Preview studies showed promissory pharmacological results by the use of this plant in the treatment of gastroduodenal ulcers. The present work involved another evaluation of the active extract important by the development of a new drug. It was evaluated by intestinal absorption in vitro and in situ models and anti-diarrheic activity in rats. The polyphenolic fractions were separated from the aqueous extract and its cytoprotective activity was studied on gastric ulceration induced by ethanol plus hydrochloric acid in rats. Some toxicological studies were carried out. We made a validation of HPLC method by the analysis of one mark in the tablet development. The aqueous extract showed high absorption, and high anti-diarrheic effect. The low-molecular weight polyphenolic fraction showed the highest level of gastric protection. No toxicological signs were obtained by it. HPLC method evidenced linearity, precision, sensitivity and accuracy.
\end{abstract}

\section{Keywords}

Rhizophora mangle L., Polyphenols, Intestinal Absorption, Genotoxicology, HPLC Analysis

\section{${ }^{*}$ Corresponding author.}

How to cite this paper: Perera, L.M.S., Piloto, J., Canelsota, D., Pelzer, L. and Mancebo, B. (2016) Further Pharmacological Evidence Supporting the Development of an Antiulcerogenic Drug Based on Rhizophora mangle L. Aqueous Extract. HPLC Method Proposed for Determinating a Chemical Marker. Open Access Library Journal, 3: e1625.

http://dx.doi.org/10.4236/oalib.1101625 


\section{Subject Areas: Biodiversity}

\section{Introduction}

Rhizophora mangle L. was widely distributed in Cuba and other Caribbean countries [1].

In previous works, we reported the cytoprotective effect of freeze dried aqueous extract from red mangrove bark on gastric ulceration induced by ethanol-hydrochloric acid in rats [2]. Also, we report the antiulcerogenic effect by other action's mechanism as antisecretor, inhibitor of depleting of PGE2 in the gastricmucous and antioxidant [3] [4].

Other preview studied performance with this extract; it had shown the presence polyphenolic structures (54.78\%) and other structural components (45.22\%). Polymeric tannins were the major polyphenolic component (80\%) and hydrolysable tannins were $20 \%$. Epicatechin, catechin, chlorogenic acid, gallic acid and ellagic acid were monomeric structures determined in this extract. Phytosterols (0.0285\%): stigmasterol, $\beta$-sitosterol and likewise campesterol were presented too [5]-[7]. This extract presents semivolatil compounds [8]—fatty acids and sugars [5], for it represents a complex mixture of secondary metabolites.

This vegetal specie with pharmacological activity as the antiulcer in gastroduodenal tract was processed by analyzing your possible toxic effect in acute and sub-acuteoral toxicology in rats. Any toxicological sign was shown in both studies [9].

For all preview studies, it is possible to consider this plant as a very good leader or source by the development of a phytomedicament. However other studies will be necessary by it, for example compounds present in total extract are responsible of the activity obtaining with the extract; studies of the security and secondary adverse effects. Regulatory requirements for drugs development request different levels of genotoxicological testing and the effect on other system in the organism.

Other aspect necessary is to determinate the quality control and the stability from new formulation. In this sense it will be proceeding to define first a chemical marker or active substance which could determinate in the end formulation, for example tablets. After defined analysis method to determinate at this substance, it is a requirement to validate a method by its sensibility and reproducibility.

The objective of the present work was to complete the study of this plant by its use in human medicine for treating gastroduodenal ulcers. These studies include completing the study of the possible adverse effects in the administration of vegetal drugs, and its effects on other biological systems: two models of intestinal absorption in vitro and in situ in rats. The activity of this extract was to test on diarrhea produced by ricin oil in rats. Other proposal of the present work was to evaluate the cytoprotective activity of the major compounds, polyphenols and the possible synergic activity of low- and high-molecular weigh polyphenolic fractions; genotoxicological tests: spermatozoa head assay and Comet's test. HLPC analysis methods to catechin determination in tablet validation were included.

\section{Materials and Methods}

\subsection{Preparations of Aqueous Extract of $R$. mangle L. Bark}

R. mangle L. was collect from the western zones of Cuba in 2011. The identity of the plant was authentifique by a botanist and a voucher specimen has been deposite in National Botanical Garden's Herbarium. The extract was prepared for the decoction of the bark in distillate water. The proportion of vegetal matter: water was 1:7; the decoction was make for $20 \mathrm{~min}$ at $90^{\circ} \mathrm{C}$ in lab reactor with $2 \mathrm{~L}$ of capacity. The plant material was separate by centrifugation and the aqueous extract was concentrated and freeze-dried to preserve it.

\subsection{Pharmacological Studies}

\subsubsection{Intestinal Absorption in Vitro Model}

In the experimental models of intestinal absorption in vitro were used small intestine segments from three animals.

The administration of aqueous freeze dried of R. mangle was make as it was representing in Table 1 . For ob- 
tain the different doses the extract was weigh considered the weigh body of three rats and enough quantity for represent 250 and $500 \mathrm{mg} / \mathrm{Kg}$ body weight and it were diluted in distillated water to obtain the doses. In each segment of small intestine were insert $0.2 \mathrm{ml}$ of each solution, and equivalent at each dose.

The selections of these doses were determinate by therapeutically answer as antiulcer effect. The concentration of tannin insert in each segment of small intestine was $30.74 \mathrm{mg}$ of tannins in $250 \mathrm{mg} / \mathrm{Kg}$ (39.68\% of tannins in the freeze dried extract by Spray-Drier). The tannin determination was make by precipitation of protein methods [10].

\subsubsection{In Situ Study to Intestinal Absorption of Freeze-Dried Extract of R. mangle} in Total Segment of Small Intestine

The absorption model was to asses as a tool for describe passive absorption mechanism and to go deeply into the structures of the physiological absorbing barriers.

The methodology consists of establishing correlations between absorption rate constants and lipophilicity for a several homologous series of xenobiotics. Figure 1 shows the closed loop perfusion technique that was used to obtain intestinal absorption rate constants in rats. The Model considers passive intestinal absorption as the result of two simultaneous processes: diffusion through aqueous channels (porous or tight junctions) and diffusion through the lipophilic membrane. The absorption rate constant is the sum of the two parallel processes [11].

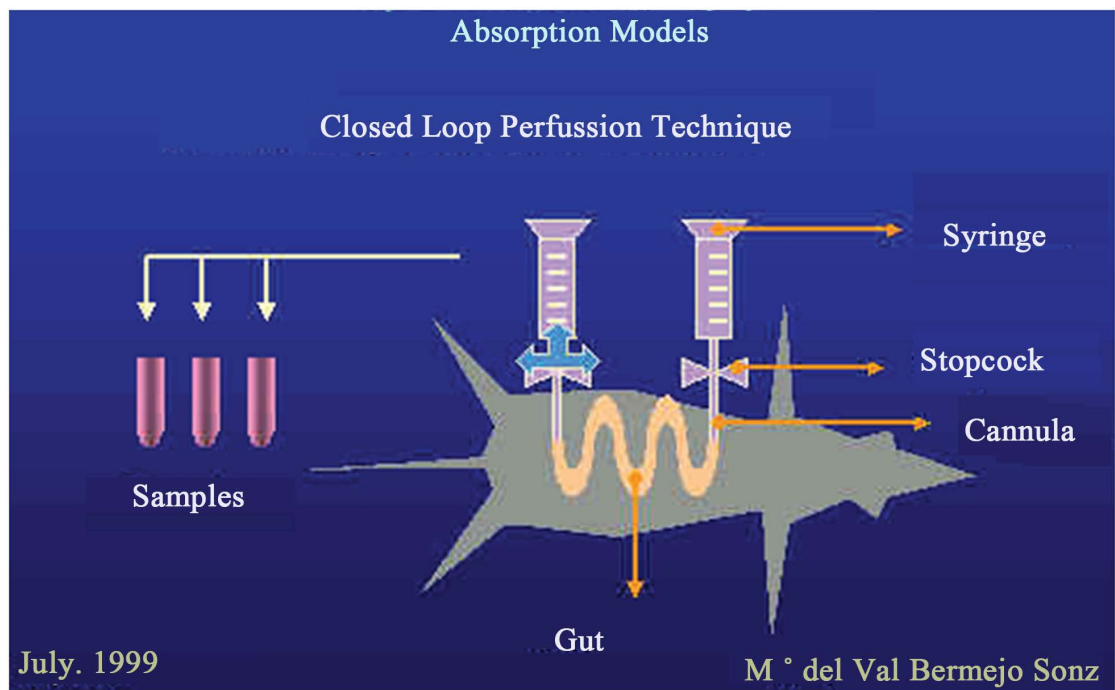

Figure 1. It shows the closed loop perfusion technique that was used to obtain intestinal absorption rate constants in rats.

Table 1. Doses of extract from $R$. mangle in the small intestine of rats.

\begin{tabular}{|c|c|c|}
\hline Part of small intestine & Segment (cm) & Doses (mg/Kg) \\
\hline \multirow[t]{4}{*}{ DUODENUM } & 6 & 250 \\
\hline & 12 & 250 \\
\hline & 18 & 250 \\
\hline & 24 & 250 \\
\hline \multirow[t]{5}{*}{ JEJUNE } & 30 & 500 \\
\hline & 36 & 500 \\
\hline & 42 & 500 \\
\hline & 48 & 500 \\
\hline & 54 & 250 \\
\hline \multirow[t]{2}{*}{ ILEUM } & 60 & 250 \\
\hline & 66 & 250 \\
\hline
\end{tabular}




\subsubsection{The Anti-Diarrheic Effect of $R$. mangle. Accumulation of Fluid in Small Intestine in Rats}

In this experiment were used Wistar rats weighing 150 - $180 \mathrm{~g}$, with 12 hours faster. Three groups were made with 5 rats by group. First group was administered with $1 \mathrm{ml}$ of vehicle after 30 minutes was administer $2 \mathrm{ml}$ of ricin oil by oral administration. Groups 2 and 3 were treatment with 125 and $250 \mathrm{mg} / \mathrm{Kg}$ b.w. of extract from $R$. mangle ( $1 \mathrm{ml}$ ), after were administered $2 \mathrm{ml}$ of ricin oil. After 30 minutes the rats were sacrificed. The small intestines were isolated by pyloric esfinger to ileocecal valvule and it were weight with intraluminal content, after the content of intestine were separated and it were weight another. The longitudes of intestines were measured. Intraluminal (enteropooling) fluid was calculated in $\mathrm{mg} / \mathrm{cm}$ with the following (W1 - W2)/L, where W1 is the weight of small intestine, W2 is the weight of empty small intestine with intraluminal content and L is the intestine longitude.

\subsubsection{Cytoprotective Activity of Polyphenolic Compounds Fractions on Experimental Gastric Ulceration}

The evaluation of gastric protection from polyphenolic fractions was make two experiments. One experiment we used the following doses: negative control with distilled water; one group with $500 \mathrm{mg} / \mathrm{kg} \mathrm{b.w.} \mathrm{of} \mathrm{freeze-dried}$ aqueous extract from $R$. mangle; a group with $100 \mathrm{mg} / \mathrm{kg}$ of high molecular weight polyphenols fraction; a group with $100 \mathrm{mg} / \mathrm{kg}$ of low molecular weight polyphenols fraction and one group using ranitidine $(100 \mathrm{mg} / \mathrm{kg}$ b.w.) as positive control. In the second experiment, we used the following groups: distillated water as negative control, two groups treated by 200 and $400 \mathrm{mg} / \mathrm{Kg}$ b.w. from high molecular weight polyphenols (HMWP); two groups treated by 200 and $400 \mathrm{mg} / \mathrm{Kg}$ b.w. from low molecular weight polyphenols (LMWP); one group with $200 \mathrm{mg} / \mathrm{Kg}$ b.w. of HMWP and $60 \mathrm{mg} / \mathrm{Kg}$ b.w. of LMWP and one group treated with $500 \mathrm{mg} / \mathrm{Kg}$ b.w. of Rhizophora mangle L. (freeze-dried). In all cases were given orally (gavage).

a) Gastric protection from polyphenolic compounds fractions

The high and low molecular weight polyphenolic fractions separation of the freeze dried aqueous extract from Rhizophora mangle L bark were employed the scheme described in the Figure 2. These fractions were resolved in water by animal administration.

b) Gastric lesions induced by necrotizing agent

Animals in testing groups were given $1 \mathrm{ml}$ of necrotic agent $(60 \mathrm{ml}$ ethanol $+1.7 \mathrm{ml}$ hydrochloric acid +38.3 $\mathrm{ml}$ water). Freeze dried $R$. mangle extract, polyphenolic fractions and ranitidine were given 30 min before the necrotic agent. Animals were killed by cervical dislocation $1 \mathrm{~h}$ after treatment with the ulcerogenic agent. The

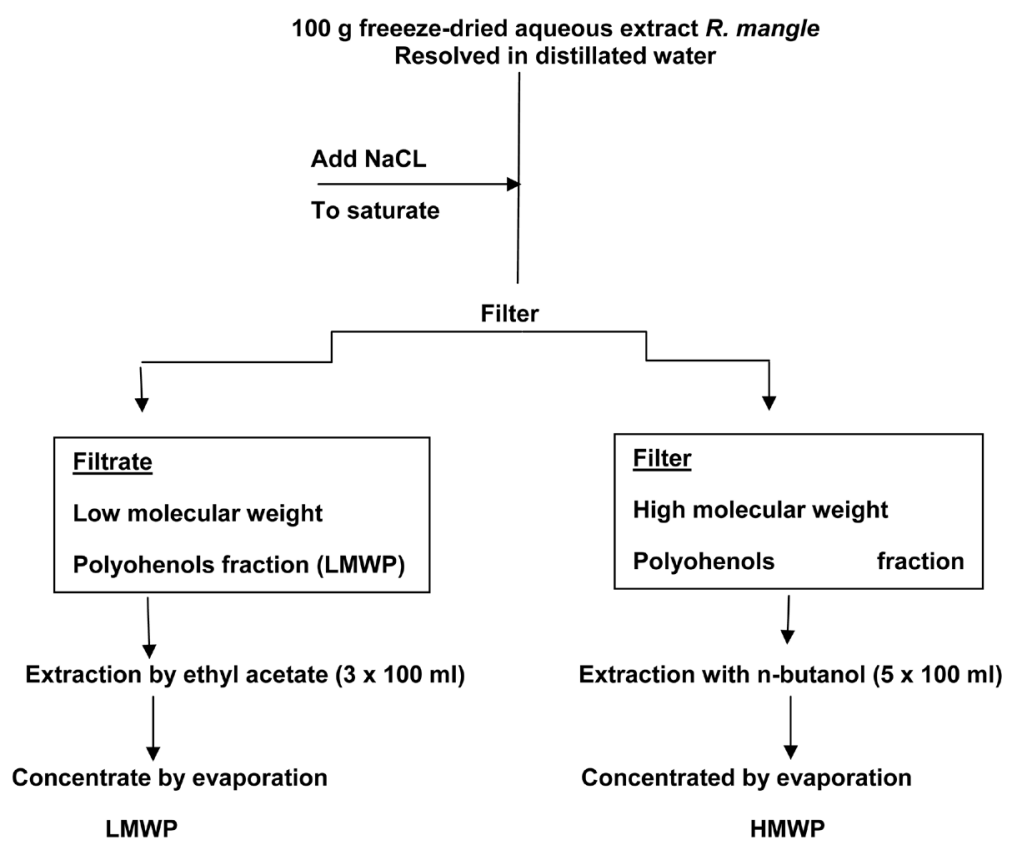

Figure 2. Low and high molecular weight polyphenols fractionation from an aqueous extract Rhizophora mangle L. 
stomach of each animal was excised and opened along the greater curvature. After washing with the normal saline, the gastric lesions were quantified using a binocular magnifier, the sum of length (in $\mathrm{mm}$ ) to alls lesions in each animal was used as a lesion index. The number of erosions per stomach was assessed for the severity according to, 1) absence of lesion, vasodilatation or up to three pinpoint ulcers; 2) more than three pinpoint ulcers; 3 ) from one to five small ulcers ( $<2 \mathrm{~mm})$; 4 ) more than five small ulcers $(<2 \mathrm{~mm})$; 5) one or more giantulcers ( $\geq 2 \mathrm{~mm}$ ).

c) Statistical analysis

The data are expressed as means \pm S.E.M. (standard deviation of the means). Student's t-test was used for statistical analysis, P values $<0.05$ were considered significant. Non-parametric data were analyzed by Wilcoxon Score test.

\subsection{Chemical Characterization}

Validation of the Method for Catechin Determination by HPLC, as a Chemical Marker in Tablets from Rhizophora mangle L.

The high-performance liquid chromatography method validation to the quantitative assessment of cathechin as a marker substance in tablets obtained from the bark of Rhizophora mangle L. dry extract used in gastroduodenal ulcers treatment. Considering that this method as such is classified to quantitative assessment of the major compound or active ingredient in formulae or raw material, the following parameters were assessed: linearity, accuracy, sensitivity and precision expressed in its two ways: repetition and intermediate precision.

Reference substance catechin was of Sigma. Phytodrugs in tablets forms were manufactured in PHARMALAB Enterprise, Guatemala.

All reactive used were pure quality by analysis.

Analytical method by High Resolution Liquid Chromatography was made with isocratic bomb Kanauer, detector UV Knauer with the following chromatographic conditions:

Column: LiChrosorb, RP-18, $5 \mu \mathrm{m}, 125 \times 4$ mm d.i.; mobile phase: Methanol: acetic acid 2\% (20:80 v/v), Detector: variable ultraviolet at $254 \mathrm{~nm}$; Flow velocity: $0.8 \mathrm{ml} / \mathrm{min}$; Injector volume: $20 \mu \mathrm{L}$. Detection System coupled at BIOCHROM program for the analysis of retention time and area of the picks.

The reference solution was made with catechin in methanol at $1 \mathrm{mg} / \mathrm{ml}$ concentration.

The fraction of ethyl acetate was obtained with 20 tablets with the addition of $100 \mathrm{ml}$ of distilled water and heated at $60^{\circ} \mathrm{C}$. It was treated with $36 \mathrm{~g}$ of sodium chloride for the precipitation of polyphenols of major molecular weight. It was centrifuge at $3500 \mathrm{rpm}$ during 15 minute at the supernatant was extracted successively with ethyl acetate (3 extractions). Ethyl acetate fraction was dried and it was dissolved in $10 \mathrm{ml}$ of methanol by the injection in HPLC.

\subsection{Genotoxicological Evaluation}

\subsubsection{Genotoxic Assessments of Aqueous Extract of Rhizophora mangle L. by Spermatozoa Head Assay}

Experiments were performed using 8 - 12 weeks, Cenp: NMRI out bred, male mice, provided by Centro para la Producción de Animales de Laboratorio (CENPALAB), Havana, Cuba. Animals were kept at room temperature and room relative humidity and exposed to the natural light-dark cycle. They were randomly distributed in groups of 6 animals per dose in each treatment, and the standard rodent diet and tap water were ad libitum. All the animal procedures reported here, were carried out in accordance with the Cuban regulations on the protection of animals. The experimental protocol was also revised by ethical committee and conducted humanely.

1) Experimental design

Three different experimental series (referred as I, II and III) were designed to evaluate the possible genotoxic effect of the aqueous extract of $R$. mangle. In all cases, the extract was dissolved in saline solution ( $\mathrm{NaCl} 0.9 \%)$ and given by oral administration using 3 different dose levels (500, 1000 and $2000 \mathrm{mg}$ of total solids/kg b.w.). An equal volume of saline solution was considered as a negative control group in all experimental series. In series I, the extract was administered during 3 days within 24 hours-time interval and the animals were humanely sacrificed on day 4 after starting the administrations. In series II, the extract was also given once per day, but the treatments lasted 5 days and the animals were sacrificed on day 21. In series III, the administrations of the extract were conducted as in series II, but the animals were sacrificed on day 35 . 
2) Sperm morphology test

The test was performed according to the method described by Wyrobek and Bruce, 1978 [12] and Dobrzyriska and Gajewski, 2000 [13]. The animals were sacrificed by cervical dislocation on days 4, 21 and 35 after the first injection, according to the different series detailed previously. Both caudal epididymus were removed and placed in a Petri plaque containing $1 \mathrm{ml}$ of saline solution. The sperms were released after mechanical disruption and washing of the epididymus. The sperms concentrations in each sample were determined by spermatic counts on Newbauer chamber (DDR, Germany). In addition, an aliquot of the sperm suspension was stained by $0.1 \%$ eosin. Briefly, a drop was taken and smeared on a clean slide, and 1000 spermatozoa of each mouse were analyzed in a DMLS microscope (Leyca, Germany) with 100× amplification. The following abnormalities were scored: lacking hook, amorphous and banana-shaped head.

3) Statistical analysis

Results of sperm count and morphology are presented as the mean \pm standard deviation (SD). Data of normal distribution and variance homogeneity were studied by Kolmogorov-Smirnov and Bartlet tests, respectively. Treatments were compared using ANOVA and Dunney’s post-test. $p<0.05$ was considered significant.

\subsubsection{Activity of Rhizophora mangle L. Aqueous Extract on Primary Injury at DNA in Mice Hepatocytes Using Comet Test}

Mice NMRI were used of both sexes. It was distributed in three experimental groups (10 animals/group): once as negative control treated with distillated water, the second group treated with $2000 \mathrm{mg} / \mathrm{Kg}$ b.w. of extract from $R$. mangle. It these case the treatment were administered for 14 days and the third group was considered as positive control and it was treated with methylmethanosulfonate (MMS) during five days before test's conclusion. The administration at negative and treatment groups were made by oral and in the case of positive group the administration was intra peritoneal. Animals were sacrificed by euthanasia 2 to 6 hours after the last administration. By the hepatocytes isolate each animal were extracted the kidney and immediately it were put in Hanks solution. It was cold on ice during 20 minutes. Portion of principal hepatic lobules was put on cold port object, courting in rectangular pieces. It was washed with $15 \mathrm{ul}$ of Sorensen buffer (50 mM, pH 7.2). They were maintained at ambient temperature 1 - 2 minutes before low fusion point of agarose addition (BPF). Alkaline electrophoresis test * (Comet Test) were made. For also, 15 - 30 ul of cellular suspension and 140 ul of low fusion point agarose $0.5 \%$ were extended in sheets preview prepared with normal fusion point $0.5 \%$. They were submerged in lisis solution (NaCL $2.5 \mathrm{M}$, EDTA $100 \mathrm{mM}$ and Tris $10 \mathrm{mM}, 1 \%$ Triton, 10\%) during 1 hour at $4^{\circ} \mathrm{C}$ and after they were submerged 30 minutes in electrophoresis regulator solution (3\% NaOH $10 \mathrm{~N}, 0.5 \%$ EDTa $200 \mathrm{mM}, \mathrm{pH}>13)$. Electrophoresis was made at $300 \mathrm{~mA}$ and $0.7-1 \mathrm{~V} / \mathrm{cm}$ during $20-30$ minutes. It was made 3 washes with neutralization regulator solution (Tris $0.4 \mathrm{M}, \mathrm{pH} 7.5$ ) and it was cleared with distillated water. The tin was made with argent nitrate (0.05\%) and the nucleoids' colored were evaluated employed an optic microscopy. By the recount on induced injury sheets were observe to optic microscopy with $40 \times$ of increase and it were classified as 50 comets/gel. Each comet was classified accord to category 0 grade of injury correspond to DNA between 0 and 4 . Injury magnitude in DNA was expressed in arbitraries unity (UA) according with Collins [14] with possible valor in range of 0 - 400, according the following equation:

$$
\mathrm{UA}=0 \times \mathrm{TCG} 0+1 \times \mathrm{TCG} 1+2 \times \mathrm{TCG} 2+3 \times \mathrm{TCG} 3+4 \times \mathrm{TCG} 4
$$

TCG0 $=$ Total cells grade 0 (not injury cells); TCG1 $=$ Total cells grade 1 (minimum frequency of lesions in DNA); TCG2 = Total cells grade 2 (low injury, with frequency low of lesions in DNA); TCG3 = Total cells grade 3 (high injury, with high frequency of lesions in DNA); TCG4 = Total cells grade 4 (cells totally injury).

Statistical analysis was made with Stat soft program by Window version 6.1. Significant was 0.05. It were used Kolmogorov-Smirnov by normality and variance homogeneity (Levene or Bartlett). Student $t$ Test were used by comparison between media inter groups.

\section{Results}

\subsection{Pharmacological Evaluation}

\subsubsection{Intestinal Absorption in Vitro Model}

In the Table 2 and Figure 3 it were shown a doses-answer results of the different doses employed, for also to increases the doses increase the tannins absorption and the tannin's content residual is low. It was demonstrated 


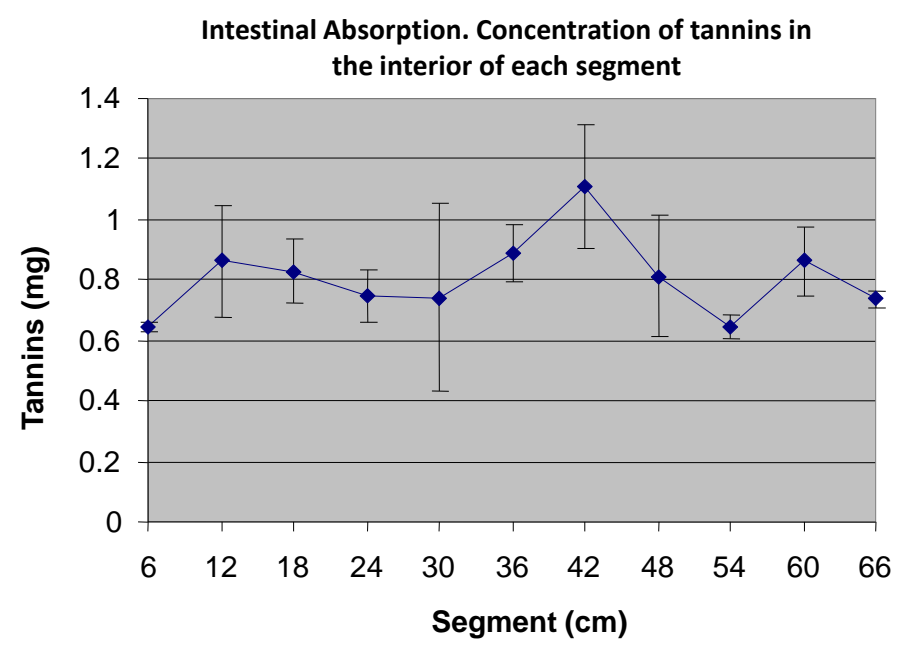

Figure 3. Concentration of residual's tannins in the interior of segment after the incubation of each segment during 5 minutes ( $n=3$ animals by segment).

Table 2. Quantity of residual and absorb tannins by each intestinal segment to insert extract of $R$. mangle in buffer.

\begin{tabular}{ccccccc}
\hline $\begin{array}{c}\text { Parte of } \\
\text { intestine }\end{array}$ & Segment & Doses & $\begin{array}{c}\text { Animal } 1 \\
\text { Content of residual } \\
\text { tannins (mg/ml) }\end{array}$ & $\begin{array}{c}\text { Animal 2 } \\
\text { Content of residual } \\
\text { tannins (mg/ml) }\end{array}$ & $\begin{array}{c}\text { Animal 3 } \\
\text { Content of residual } \\
\text { tannins (mg/ml) }\end{array}$ & $\begin{array}{c}\text { Media } \pm \text { D.S. } \\
\text { Content of residual } \\
\text { tannins }(\mathrm{mg} / \mathrm{ml})\end{array}$ \\
\hline DUODENUM & 6 & 250 & 0.309 & 0.287 & 0.283 & $0.293 \pm 0.014$ \\
& 12 & 250 & 0.290 & 0.291 & 0.283 & $0.288 \pm 0.004$ \\
& 18 & 250 & 0.289 & 0.311 & 0.281 & $0.294 \pm 0.015$ \\
& 24 & 250 & 0.3093 & 0.291 & 0.283 & $0.294 \pm 0.013$ \\
& 30 & 500 & 0.286 & 0.292 & 0.273 & $0.284 \pm 0.01$ \\
& 36 & 500 & 0.281 & 0.288 & 0.277 & $0.282 \pm 0.005$ \\
& 42 & 500 & 0.294 & 0.286 & 0.277 & $0.286 \pm 0.008$ \\
& 48 & 500 & 0.293 & 0.286 & 0.277 & $0.285 \pm 0.008$ \\
& 54 & 250 & 0.283 & 0.293 & 0.288 & $0.288 \pm 0.005$ \\
\hline & 60 & 250 & 0.289 & 0.288 & 0.286 & $0.288 \pm 0.001$ \\
\hline
\end{tabular}

that the content of residual tannins in $250 \mathrm{mg} / \mathrm{kg}$ b.w. is similar in duodenum, jejune and ileum. These results suggest that the absorption of tannins not depend of intestinal segment. The absorption in gut of tannins in the freeze dried extract of $R$. mangle is superiority at $97 \%$. These results suggest that the polyphenols present in the extract are polyphenols with high absorption, for also these compounds are structures with relative low molecular weigh structure (monomer, dimer or trimer) and don't present polymeric compounds.

In situ study to intestinal absorption of freeze dried extract of $R$. mangle in total segment of small intestine.

The parameter representative of absorption process using was the constant apparent of absorption rate (kap) because it represents an index of the absorption rate intrinsic off solute.

This constant was determinate within recirculation evading the aqueous layer of adjacent diffusion to the membrane.

It in situ method was choice because it plows considered in general reproducible with it lives reliable the absorption process whom occur in vivo. The perfumed volume stay all time to testing (30 minutes) in contact with intestinal mucosa, for also the absorption yield is high than that the obtain by other techniques, where the con- 
tact fluid-mucosa is intermittent. In this method is it maintains blood flow and tisular integrity similar at in vivo models.

In the Table 3 shown the results of this experiment by freeze dried extract of $R$. mangle L. The constant apparent of absorption rate was $2.03 \pm 0.77$. For also, this study verify the high absorption of extract of $R$. mangle obtain in vitro.

\subsubsection{The Anti-Diarrheic Effect of $R$. mangle. Accumulation of Fluid in Small Intestine in Rats}

The accumulation of fluid in small intestine in rats is quick, qualitative and predictive of diarrhea and it is useful to research agents that block this effect. The accumulation of fluid in small intestine in named "enteropooling". This accumulation is a sum of fluid secreted from blood to lumen and a portion of fluid of lumen that absorption is inhibit by prostaglandin or other laxante agents as ricin oil hypertonic's solution that cause enteropooling too.

Ricin oil increase a volume of intestinal fluid, this effect is maximum to 30 minutes, which it reduces the fluid accumulation. The Figure 4 showed the activity of aqueous extract of $R$. mangle on fluid accumulation, decreasing doses-dependence with significantly $(p<0.01)$ respect to control group.

\subsubsection{Gastric Protection Activity from Polyphenolic Compounds Fractions}

First, we made a preliminary test of the cytoprotective effect of freeze dried aqueous extract of Rhizophora mangle L. in a acute ulcer model induced by ethanol plus hydrocloride acid (6). But, we not defined what compounds was responsible of this activity. This extract was different structural compounds: fatty acids, phytosterols, volatile compounds and polyphenols as major secondary metabolites.

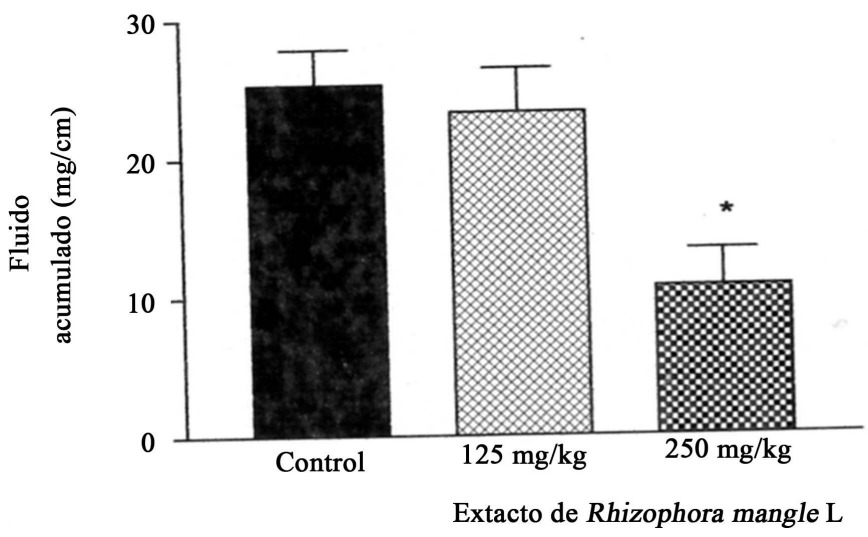

Figure 4. Accumulation of fluid induced by ricin oil. Activity of extract from $R$. mangle ( $\mathrm{n}=5$ animals, $\left.{ }^{*} p<0.01\right)$.

Table 3. Concentration of remnant tannins $(\mathrm{mg} / \mathrm{ml})$ in intestinal lumen at different time to sample taking alter the perfusion of extract from $R$. mangle at equivalent concentration to doses of $250 \mathrm{mg} / \mathrm{Kg}$ b.w. (0.8285 mg/ml total tannins).

\begin{tabular}{|c|c|c|c|c|c|c|}
\hline \multicolumn{7}{|c|}{ Extract $250 \mathrm{mg} / \mathrm{Kg}$ b.w. $\mathrm{C}_{0}=0.8285 \mathrm{mg} / \mathrm{ml}$} \\
\hline \multirow{3}{*}{ Time (min) } & \multicolumn{6}{|c|}{ Remnant concentration in the lumen $=\mathrm{C}=\mathrm{mg} / \mathrm{ml}$} \\
\hline & \multicolumn{6}{|c|}{ Experimental Animals } \\
\hline & 1 & 2 & 3 & 4 & 5 & 6 \\
\hline 5 & 0.5528 & 0.1744 & 0.2449 & 0.2162 & 0.2945 & 0.6389 \\
\hline 10 & 0.37014 & 0.1379 & 0.2053 & 0.2018 & 0.1444 & 0.5267 \\
\hline 15 & 0.3023 & 0.1366 & 0.1679 & 0.1705 & 0.1340 & 0.5254 \\
\hline 20 & 0.2632 & 0.1314 & 0.1666 & 0.1575 & 0.1131 & 0.4850 \\
\hline 25 & 0.241 & 0.1275 & 0.1601 & 0.1366 & 0.0792 & 0.3988 \\
\hline 30 & 0.1835 & 0.1066 & 0.1249 & 0.0909 & 0.074 & 0.1797 \\
\hline
\end{tabular}

Kap (h-1): 2.03100775; D.E.: 0.76895328. Kap: constant of apparent rate of absorption. 
In the first experiment with simple doses the low and high molecular weight polyphenols fractions (100 mg/ $\mathrm{kg}$ b.w.) we found a decreasing in lesion index respect to negative control but it was not statically significant (Table 4). The major activity was shown by total aqueous extract comparable with ranitidine. For also, the gastric protection shown by aqueous extract is possible a synergic effect of different compounds present in this extract and it effect was lost in a fractionation process.

In the study of gastric protection effect by low and high molecular weight polyphenolic fractions using different doses level (experiment 2) was shown that low molecular weight polyphenolic fraction had the major cytoprotector activity (Table 5). The best respond was obtained by LMWP in dose of $400 \mathrm{mg} / \mathrm{kg}$ b.w., by a significant $p<0.05$.

It was found a doses dependent decreasing in the lesion score in both cases (treatment with HMWP and LMWP). There is not additive effect between both fractions. It was confirmed in the group treated with 200 $\mathrm{mg} / \mathrm{kg}$ HMWP more $60 \mathrm{mg} / \mathrm{kg}$ LMWP, where the action or LMWP was capable to decrease the lesion score.

Animal group treated by freeze dried aqueous extract of $R$. mangle $(500 \mathrm{mg} / \mathrm{Kg})$ was best answer than a group treated with a mixing of both fractions in the same proportion of calculated concentration of these substances in total extract. For also, we could to consider that the gastric protection activity of total aqueous extract was influence by other compounds present in this extract. These other compounds increase the gastric activity and this activity is lost in the fractionation process.

\subsection{Chemical Characterization}

Validation of Catechin Determination by HPLC, as a Marker in Tablets from Rhizophora mangle L. Results obtained showed that this method is reliable allowing the compound assessment in presence of other substances, including excipients and auxilliary substances and to detect the presence of degradation products. Also, the statistical processing of results evidenced the linearity, precision, sensitivity and accuracy of this method.

The Figure 5 showed the chromatogram of reference substance after termolisis process. In this figure could be observed not modification respect to patron's neither profile nor respect auxiliary substances. However in nucleus, filmic and enteric tablets shown a fusion between a peak at retention time 8 min with the catechin peak at $10.45 \mathrm{~min}$.

Table 4. Effect from low and high molecular weight polyphenols in a simple dose on gastric protection.

\begin{tabular}{|c|c|}
\hline & Lesion Index \\
\hline Treatment & (Media \pm E.S.M.) (mm) \\
\hline Negative Control & $42.4 \pm 11.9$ \\
\hline Freeze dried red mangrove $500 \mathrm{mg} / \mathrm{Kg}$ b.w. & $13.2 \pm 8.0^{* *}$ \\
\hline HMWP 100 mg/Kg b.w. & $37.5 \pm 23.1$ \\
\hline LMWP 100 mg/Kg b.w. & $25.4 \pm 17.8$ \\
\hline Ranitidine 100 mg/Kg b.w. & $10.8 \pm 9.1^{* *}$ \\
\hline
\end{tabular}

Table 5. Low and high molecular weight polyphenols effect on gastric protection using increasing doses.

\begin{tabular}{|c|c|}
\hline & Lesion Score \\
\hline Treatment & (Media \pm E.S.M.) (mm) \\
\hline Negative Control & $4.2 \pm 0.84$ \\
\hline HMWP 200 mg/Kg b.w. & $4 \pm 0$ \\
\hline HMWP 400 mg/Kg b.w. & $3.4 \pm 0.55$ \\
\hline LMWP 200 mg/Kg b.w. & $3.2 \pm 0.84$ \\
\hline LMWP 400 mg/Kg b.w. & $1.8 \pm 0.45^{* *}$ \\
\hline HMWP 200 mg/Kg + LMWP 60 mg/Kg b.w. & $3.5 \pm 1.00$ \\
\hline Freeze dried red mangrove 500 mg/Kg b.w. & $2.75 \pm 0.50^{*}$ \\
\hline
\end{tabular}




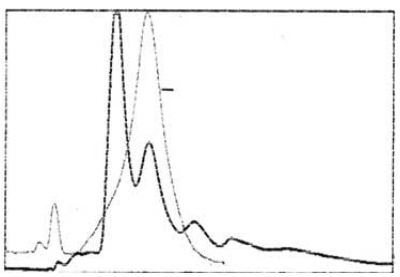

(a)

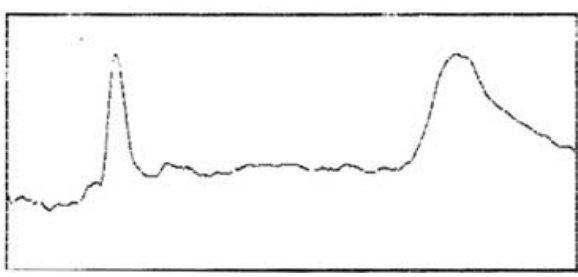

(b)

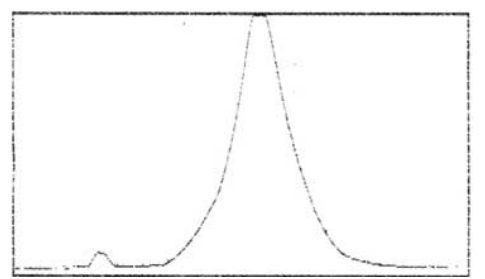

(c)

Figure 5. Chromatograms of reference substance, tablet and placebo in normal condition ((a) and (b)). Chromatogram of catechin after thermal process (c). X, means time in minute and Y, optical density.

Catechin patron was not discomposed by the action of Hydrogen peroxide $\left(\mathrm{H}_{2} \mathrm{O}_{2}\right)$. The concentration of catechin calculated after oxidation process was $1.5 \mathrm{mg} / \mathrm{ml}$, for also it guarantees not oxidation itself. In case of filmic placebo appear a new peak at $\mathrm{Rt}=11.90$, it was an interference in the catechin determination.

In chromatogram from filmic tablets after acid hydrolysis appearance catechin peak and a new peak to Rt $=$ 15.70 minutes possibly fluroglucinol.

In case of basic hydrolysis to catechin patron appearance equal to acid hydrolysis a new peak at Rt $=14.86$, for also it produced decomposition product that not interference with mark determination.

The calibration curve resulted lineal in the analysis concentration ranges, the correlations coefficient valor and determination were more than 0.99 . Student's $t$ test application with $t$ calc $>t$ tab were shown lineal correlation between $\mathrm{x}$ and $\mathrm{y}$ valor. Variation coefficient of the pendant was minor or equal that this parameter limit $(<2 \%)$.

Precision study, variation coefficient for the repeat was $2.81 \%$, less than $5 \%$.

Precision in intermediate conditions shown no significant difference between the results obtain by analysts because to made Fisher test was obtain F exp < F tab for proportionality of 0.05. Student's t Test shown that calculated valor was minor to tabulate valor for $95 \%$ of confidante. For also it was shown significant difference between analyzer's media.

The method's robust is adequate because is this not significant differences between media of areas to chance conditions as lot of mobile phase, test day and column.

The method showed a good exactly as placebo and tablets as matrix with recuperate major $80 \%$.

For also, HPLC method proposal present a detection limit of $0.002376 \mathrm{mg} / \mathrm{tab}$ and quantity limit of 0.01364 $\mathrm{mg} / \mathrm{tab}$. It method was sensible, by determination of marker in tablets.

\subsection{Genotoxicological Evaluations}

\subsubsection{Sperm Morphology Test}

The effect of the oral administration of the aqueous extract of $R$. mangle in terms of germ cells viability is presented in Table 6. The spermatic count was statistically similar in control animals and animals treated with the different dose (500; 1000; $2000 \mathrm{mg} / \mathrm{kg}$ b.w.) of $R$. mangle aqueous extract.

Results of the sperm morphology test, conducted in the three different experimental series are shown in Table 7. In experimental series I, the exposure to the highest dose of the plant extract ( $2000 \mathrm{mg} / \mathrm{kg} \mathrm{b.w.)} \mathrm{produced} \mathrm{an}$ increase of anomalous sperms, with prevalence of hook and banana type cells. However, the effect was not observed after exposure to the lower dose of the plant extract (500 and $1000 \mathrm{mg} / \mathrm{kg}$ ). On the other hand, in experimental series II and III, no increment in the frequency of appearance of anomalous head was registered after exposure to the plant extract.

On the other hand, in series II and III we appreciated that none of the doses of the aqueous extract $(500,1000$ and $2000 \mathrm{mg} / \mathrm{kg}$ b.w.) induced variations in the percentage of appearance of anomalous sperms when it is compared with the values in the control group of mice treated with saline solution ( $\mathrm{NaCl} 0.9 \%)$.

\subsubsection{Activity of Rhizophora mangle L. Aqueous Extract on Primary Injury at DNA in Mice} Hepatocytes Using Comet Test

In daily clinical inspection any animals showed toxic signs.

In Table 8 shown that the group treated with mutagenic substance was significant different to control group.

It was demonstrated an acceptable genotoxicological answer induced in hepatocytes. Though it was possible evaluate the activity on injuries index on comet Test in mice's hepatocytes treated with Rhizophora mangle L. 
Table 6. Sperm counts in NMRI mice treated with Rhizophora mangle L.

\begin{tabular}{cccc}
\hline \multirow{2}{*}{ TRATAMIENTOS } & \multicolumn{3}{c}{ CONCENTRACIÓN (10 $\mathbf{6} / \mathbf{M L})$} \\
\cline { 2 - 4 } & Series I (4 DÍAS) & Serie II (21 DÍAS) & Serie III (35 DÍAS) \\
\hline NaCl 0.9\% & $15.65 \pm 3.90$ & $13.43 \pm 4.36$ & $14.14 \pm 2.02$ \\
R. mangle 500 & $13.84 \pm 2.02$ & $13.51 \pm 1.82$ & $12.17 \pm 1.51$ \\
R. mangle 1000 & $16.11 \pm 4.53$ & $13.86 \pm 3.34$ & $11.95 \pm 3.25$ \\
R. mangle 2000 & $14.53 \pm 4.46$ & $12.75 \pm 2.86$ & $9.70 \pm 4.13$ \\
\hline
\end{tabular}

Table 7. Results of sperm morphology assy in NMRI mice treated with Rhizophora mangle L.

\begin{tabular}{cccc} 
Treatments & & Percentage of Abnormal Spermatozoa (\% \pm SD) \\
\cline { 2 - 4 } Control & Series I & Series II & $2.9 \pm 0.4$ \\
R. mangle 500 & $2.9 \pm 0.8$ & $3.1 \pm 0.3$ & $3.4 \pm 0.7$ \\
R. mangle 1000 & $2.9 \pm 0.5$ & $3.3 \pm 1.0$ & $3.6 \pm 0.8$ \\
R. mangle 2000 & $3.3 \pm 0.9$ & $2.7 \pm 0.6$ & $3.5 \pm 0.5$ \\
\hline
\end{tabular}

Values represent means \pm standard deviation (SD) of the experiments ( $n=6 /$ doses). ANOVA and Dunney post test $(p<0.05)$.

Table 8. Injuries index in DNA in Comet Test in counted of arbitrary units.

\begin{tabular}{|c|c|c|}
\hline Doses & Sex & $(\mathrm{X} \pm \mathrm{DE})$ \\
\hline \multirow{3}{*}{ Sterile Water } & M & $33.8 \pm 3.05$ \\
\hline & & \\
\hline & $\mathrm{H}$ & $31.3 \pm 6.44$ \\
\hline \multirow{2}{*}{2000 mg/Kg p.c. } & M & $44.3 \pm 10.7$ \\
\hline & $\mathrm{H}$ & $37.25 \pm 11.7$ \\
\hline \multirow{2}{*}{ Methylmethanosulfonate } & M & $150.5 \pm 5.73^{*}$ \\
\hline & $\mathrm{H}$ & $144.8 \pm 12.1^{*}$ \\
\hline
\end{tabular}

${ }^{*} p=0.05$.

freeze-dried extract. Not statistical significant difference was shown between treated group and negative control group in both sexes. The injuries index in DNA in major Comets observed in experimental groups were 0 and 1 (low injury level). Only in group treated with metylmethanosulfonate shown a migration of DNA classified in 3 or 4 level (high or extreme injury).

\section{Discussion}

The major active principles of the red mangrove are polyphenols, represented in their majority by polymerictannins (80\%) and hydrolysable tannins (20\%) and special emphasis has been given to the presence of epicathechin, catechin, chlorogenic, gallic and elagicacids, as well as galotannins, elagitannins and condensed tannins [5] [7]. These substances characterized by their polyphenolic nature, have shown cytoprotective properties [11] and have been associated to antiulcerogenic activity in other plants [15]-[18].

Tannins or polyphenols have a number of physical and chemical properties in common, which underlie their physiological and pharmacological actions: their antioxidant and radical scavenging activities and their ability to complex with other molecules such as proteins and polysaccharides [19] [20].

Vegetable polyphenols are known to inhibit lipid peroxidation in vitro and there is evidence about their ability to scavenge radicals such as hydroxyl, superoxide, and peroxyl, which are important in cellular prooxidant states. 
Incidentally, it has been shown that chlorogenic acid has antioxidant effect as high as DL-tocopherol [21].

On the other hand, tannins may prevent ulcer development due to their protein precipitating and vasoconstriction effect [22]. Their astringent action can help precipitating microproteins on the ulcer site, thereby forming an impervious layer over the lining that hinders gut secretions and protects the underlying mucosa from toxins and other irritants [23]-[25]. This propensity to bind to proteins also explains the fact that polyphenols inhibit enzymes tested in vitro.

The topical action of the aqueous extract of $R$. mangle in accelerating wound healing has been explained by several mechanisms, such as coating the wound, forming complexes with proteins of microorganism cell wall, chelating free radicals and reactive oxygen species, stimulating the contraction of the wound and increasing the formation of new capillaries and fibroblasts [21]. In our study, a thick coating of $R$. mangle extract was found macroscopically adherent to the gastric mucosa, which suggests that in addition to antioxidant mechanisms, we could be inferred that the formation of a physical barrier with similar properties as observed in topical wounds may contribute to the gastroprotective action of the drug.

The presence of fatty acids in Rhizophora genera was not reported before [26].

Essential oils, phytosterols and glycosides of Marsclemiacondurango are effectiveness in ulcer gastriccarcinoma and bleeding. Phytosterols have antiulcer effect, with protective action against Helicobacter pylori.

In recent study phytosterols esters of an herb of Dolichus genera was protective in a model of pyloric ligation ulcer [27].

Fatty acids have protective effect against pepticulce ration in several experimental models [28]. Fatty acids have antimicrobial activity. For example the presence of capric, lauric, miristic, palmitic, behemic acids in the flowers of Moltikiacaerulea have a significant antimicrobial activity at a concentration of 100 ug [29].

For also, we could be inferred that the presence of fatty acids and other functional chemical groups present in this aqueous extract as semivolatile compounds, phytosterols, carbohydrate joint at the major functional group, tannins [5] are the responsible of pharmacological activities of this plant as combinatory complex chemistry in the pharmacological finding.

The aqueous extract of $R$. mangle not has toxic effect in acute and sub-acute toxicity study [9]. In this case was shown not genotoxicity effect in bony marrow micronucleus in mice.

In the last decade the antimutagenic study had been associated to modulation of enzymes from xenobiotic's metabolism. In this case the plants had shown antimutagenic capacity by its heterogeneous compounds. Between them have a high potential antimutagenic the polyphenols of green tea. Epigallocatechin 3-gallate is an inhibitor of some enzymes of fase I as the citocrom P450, CYP1A, 2B1 and 2E1 and the ellagic acid as inductor of detoxification enzyme (fase II) as the GSTS and NAD (P) Hquininereductase. These polyphenol decrease significantly the incidence of carcinoma produced by the exposition at aromatic polycyclic hydrocarbons because they reduce the activity of benzo (a) pirenehidroxilase [30].

When evaluating the effect of the aqueous extract of $R$. mangle over the germinal cells viability it was shown that it does not induce cytotoxicity on the sperm tides that are in differentiation roads to sperms (spermatogenesis phase) or on the sperms that are already formed at 4, 21 or 35 days, corresponding to experimental series I, II and III respectively. Altogether, these results reveal that the plant extract does not affect neither the viability of the primary and secondary spermatocytes (meiosis phase) nor the viability of the spermatogonium (mitosis phase).

The absence of toxicity observed in germinal cells after exposure to the aqueous extract of the bark of $R$. mangle can be explained on the basis of its chemical components. No toxic effects on in vivo models have been attributed to condensed and hydrolysable tannins, phytosterols, semi volatile compounds and fatty acids, which are constituents of $R$. mangle aqueous extract [21]. Similarly, it has reported no toxic effects on germs cells viability after exposure to limit dose of the extracts of caisimón of anis (Piper auritum H.B.K) and majagua (Hibiscus elatus Sw), which also contain tannins in their chemical composition [31]. In addition, no toxic effects have been found for high doses (1000 and $2000 \mathrm{mg} / \mathrm{kg}$ ) of the aqueous extract of Mangifera indica L., which contains an important amount of polyphenolic compounds [30].

However, a significant increase in abnormal spermatozoa was observed in the group administered with the higher dose of the plant extract within the experimental series I, pointing out to a genotoxic effect on the germ cells, particularly at the spermatogenesis phase. The finding could be related to certain components of the extract such as hydrolysable tannins (e.g. gallic and ellagic acids) or its metabolites able of exert toxicity particularly during the spermatogenesis process.

Researchers have documented the in vitro cytotoxicity and genotoxicity induced by ellagic and gallic acid (15 - 
$240 \mathrm{mM}$ concentration range) as measured in culture of B14 cell line [32]. The results of this study showed that tannins could decrease the viability of cells and their cytotoxicity was highest at the concentration of $60 \mathrm{mM}$. Also the data obtained from the Comet assay also supported the ability of both compounds to contribute to formation of DNA single-strand breaks. Although, both chemical entities could be at least partially responsible for the mutagenic effect of the $R$. mangle extract at high doses, we thinks that in this case we must be cautious and careful because these elements are common in our diets.

On the other hand, the mutagenic effect of the extract could be also related to the lacking of effective cell repair mechanisms at this stage or to the nature of the damage, as in some cases no endogenous mechanism exists for its reparation. In any case, the values of anomalous sperms observed at the higher dose of $2000 \mathrm{mg} / \mathrm{kg}$ fall below the values reported in similar studies [31] even though they are significant when compared to control group. Consequently, above results generates questions that should be corroborated and discussed in further studies.

Current results show biggest susceptibility in the sperm tides cells, in disagreement with previous approaches in which the late spermatogonial cells and/or early primary spermatocytes appear to be the most susceptible [12] [33] [34]. But in support of our finding, researchers have also found the late sperm tides undergoing differentiation process and the sperms already formed as preferable targets of the genotoxicity, exerted by the independent and combined treatment of acryl amide and X-rays on the germinal and somatic cells [13].

The exposure to $R$. mangle aqueous extract lasting 21 and 35 days did not increase the frequency of appearance of anomalous sperms, according to the data in experimental series II and III. One line of thoughts, guided by results of Wyrobek and Bruce, 1978 [12] could lead us to conclude that $R$. mangle aqueous extract does not induce DNA damage in germ cells on mitosis and meiosis stages. But, a second view should be also considered, as certain genotoxicity of the extract was observed in experimental series I at high doses. Therefore, it can be speculated the occurrence of genotoxicity after exposure to $R$. mangle extract, which could be generally repaired, except during certain conditions, such as those observed in experimental series I. Above considerations could be perfectly permissible as strong genetic cellular control exists in the organism designed to allow the minimal quantity of mutations to be transmitted to progeny cells.

R. mangle (red mangrove) represents an ethno botanically relevant plant in Cuba, traditionally used for different biomedical applications [35]. It's variety of empirical uses with different doses, frequencies of administration and duration of treatments, make necessity to perform a complete set of toxicity studies. Current investigation gives one step towards this general purpose and demonstrates the occurrence of moderate genotoxic effects at doses 4 times higher than maximum therapeutic dose.

Nair et al., 2008 [36] shown epicatech in compound present in tea, apples and chocolate has antioxidant activity and it has protector effect on induced injury at DNA molecule by rupture of chains for gamma radiation.

Absorption is a complex problem; for also many works had been made to prediction of absorption potentiality in candidate to drugs, for this important in the biodisponibility of itself. It is necessary ground in the knowledge of absorption mechanism and metabolism of substance clinically active.

In vitro model have high complex and it not evaluated many factors in the absorption. In situ models in general reproduce with more dependability the absorption process that had been place in vivo [11] [37]. In the absorption process could be considered four important aspects: to step of digestive tube across esophagi, dissolution of the drugs in small particles; absorption to stomach level but principally in intestine and the drugs absorbed in blood circulation are distribute in the body and in different tissue [38].

Polyphenols-flavonoids, phenolic acids and tannins - are contained in several foods of plant origin (fruit and vegetables). Much evidence has been provided in recent years supporting a role for these compounds as protective agents against cardiovascular disease and certain forms of cancer, including breast, esophageal, gastrointestinal, lung and skin cancer. Increasing evidence for the possible effects of plant polyphenols on human health have been obtained in in vitro and in vivo systems. However, data on their absorption from the gastrointestinal tract are still scarce and, often, contradictory, although it is likely that the different biological effects of polyphenols are related to their absorption and bioavailability for target organs and tissues. Polyphenol bioavailability was evaluated using segments of the small intestine of rats. Two polyphenolic compounds, tannic acid and catechin, were tested in our model system as representatives of high and low molecular weight polyphenols with gallic acid and flavonoid structures, respectively [38].

There have been several human studies that have investigated the absorption and bioavailability of flavonoids. Initially, absorption of flavonoids from the diet was believed negligible, given that the majority of food flavonoids are bound to glycosides. It was expected that the aglycones only could pass freely into the bloodstream 
from the gut wall, because no enzymes are secreted in the gut that could cleave the glycosidic bonds. Recent studies, however, have demonstrated that he bioavailability of specific flavonoids is much higher than previously believed [39] [40].

The bioavailability of polyphenols is reviewed, with particular focus on intestinal absorption and the influence of chemical structure (e.g., glycosylation, esterification, and polymerization), food matrix, and excretion back into the intestinal lumen. Information on the role of microflora in the catabolism of polyphenols and the production of someactive metabolites is presented. Mechanisms of intestinal and hepatic conjugation (methylation, glucuronidation, and sulfation), plasma transport, and elimination in bile and urine are also described [41].

Proanthocyanidins differ from most other plantpolyphenols because of their polymeric nature and highmolecular weight. This particular feature should limit their absorption through the gut barrier, and oligomers larger than trimers are unlikely to be absorbed in the small intestine in their native forms. In vitro experiments using single layers of Caco-2 cells as a model of absorption in the small intestine showed that only the dimers and trimmers of flavanols are able to cross the intestinal epithelium. Procyanidin B2 is very poorly absorbed in rats, whereas procyanid in B3 is not absorbed. The possibility that procyanidin oligomers are hydrolyzed to mixtures of flavanol monomers and dimers in acidic conditions was suggested by Spencer et al. [42] from in vitro experiments. However, purified procyanidin dimer B3 as well as grape seed proanthocyanidins having a higher degree of polymerization, are not degraded to more readily absorbable monomers in rats. The stability of proanthocyanidins was investigated in humans by regular analysis of gastric juice sampled with a gastric probe after ingestion of a proanthocyanidin-rich cocoa beverage. This study confirmed that proanthocyanidins are not degraded in the acidic conditions of the stomach in vivo. A minor absorption of some procyanidin dimers seems possible in humans. The procyanidindimer B2 was detected in the plasma of volunteers after ingestion of a cocoa beverage; however, the maximal plasma concentration that was reached $2 \mathrm{~h}$ after ingestion was much lower than that reached after a roughly equivalent intake of epicatechin $(0.04$ compared with $6.0 \mathrm{~mol} / \mathrm{L})$. Proanthocyanidins, which are among the most abundant dietary polyphenols, are very poorly absorbed and may exert only local activity in the gastrointestinal tract or activity mediated by phenolicacids produced through microbial degradation [41].

The freeze dried extract of $R$. mangle as active principle in antiulcer effect has more than $50 \%$ of tannins identify principally proanthocyanidins (monomer and oligomer). For also the results obtain in this report about it absorptionby in vitro and in situ models could be verify the report of other author in the field of absorption and bioavailability of polyphenols in animals and in human. Our found coincide by other report about the antiulcerogenic activity for some polyphenols [43]-[46].

\section{Conclusion}

The freeze-dried aqueous extract of $R$. mangle is with a high concentration of high molecular weigh polyphenols. We demonstrated that the cytoprotective effect of this extract in peptic ulcer is a synergic effect of polyphenolic structures more than other secondary metabolites present in the aqueous extract. The extract possessed antidiarrheic activity and it had a high absorption in in-vitro and in-vivo models which warrant the biodisponibility of this extract in the body. The extract does not have secondary effect in genotoxicological test. Catechin was validated as a good chemical mark in the development of phytodrugs with this plant.

\section{References}

[1] Roig, J.T. (1974) Medicinal, Aromatic and Dangerous Plants from Cuba. Editorial Revolución y Progreso, La Habana, 745.

[2] Sánchez, P.L.M., Ruedas, D. and Gómez, B.C. (2001) Gastric Antiulcer Effect of Rhizophora mangle L. Journal of Ethnopharmacology, 77, 1-3. http://dx.doi.org/10.1016/S0378-8741(01)00277-X

[3] Sánchez, P.L.M., Niurka, Y.B., Rodríguez, A., Farrada, F. and Bulnes, C. (2004) Gastric and Duodenal Antiulcer Effects of Rhizophora mangle L. Pharmaceutical Biology, 42, 225-229. http://dx.doi.org/10.1080/13880200490514096

[4] Berenguer, B., Sánchez, L.M., Quilez, A., López-Barreiro, M., de Haro, O., Gálvez, J. and Martin, M.J.J. (2006) Protective and Antioxidant Effects of Rhizophora mangle L. against NSAID-Induced Gastric Ulcers. Journal of Ethnopharmacology, 103, 194-200. http://dx.doi.org/10.1016/j.jep.2005.08.029

[5] Sánchez, P.L.M., Melchor, G., Álvarez, S. and Bulnes, C. (1998) Chemical and Toxicological Characterization of One Wound Healing Formulation form Rhizophora mangle L. Revista de Salud Animal, 20, 69-72. 
[6] Edith, L., Steingas, H. and Menice, K.H. (1991) Tannins in Ruminant Feed Stuffs. Separate Print Animal by the Institute for Scientific Cooperation. Institute for Scientific Cooperation, 33, 9-62.

[7] Sánchez, P.L.M., Varcalcel, L., Escobar, A. and Noa, M. (2008b) Polyphenol and Phytosterols. Composition in an Antibacterial Extract from Rhizophora mangle L.'s Bark. Journal of Herbal Pharmacotherapy, 7, 107-128. http://dx.doi.org/10.1080/15228940802142720

Labieniec, M. and Gabryelak, T. (2003) Effects of Tannins on Chinese Hamster Cell Line B14. Mutation Research, 39, 127-135. http://dx.doi.org/10.1016/S1383-5718(03)00161-X

[8] Pino, J.A., Marbot, R., Aguero, J. and Sánchez, L.M. (2001) Volatile Components of Red Mangrove Bark (Rhizophora mangle L.) from Cuba. Journal of Essential Oil Research, 13, 88-89. http://dx.doi.org/10.1080/10412905.2001.9699622

[9] Sánchez, P.L.M., Ivis, F.C., Betty, M.D. and Rafael, L.M. (2008a) Oral Acute and Subacute Toxicological of Freeze Dried Aqueous Extract of Rhizophora mangle L. in Rats. Revista Cubana de Plantas Medicinales, 13, 1-13.

[10] Travieso, M.C., Hechavarria, O., Betancourt, A., Frontela, M. and Miranda, I. (1998) Validación del método de determinación de taninos totales en productos naturales vegetales. Revista de Protección Vegetal, 13, 189-194.

[11] González Álvarez, M.A. (2002) Estudio in situ e in vitro de los mecanismos de absorción y secreción intestinal del 3'metilciprofloxacino. Doctoral Thesis Doctoral, Facultad de Farmacia, Universidad de Valencia, Valencia.

[12] Wyrobek, A.J. and Bruce, W.R. (1978) The Induction of Sperm Shape Abnormalities in Mice and Humans. Chemical Mutagens: Principles and Methods for Their Detection. A Hollander and FH de Serres Plenum Press, New York, $257-$ 285.

[13] Gajewski, D.M. (2000) A Induction of Micronuclei in Bone Marrow and Sperm Head Abnormalities after Combined Exposure of Mice to Low Doses of X-Rays and Acrylamide. Teratogenesis Carcinogenesis Mutagenesis Journal, 20, 133-140.

[14] Klaude, M., Ericson, S., Nygren, J. and Ahnstro, G. (1996) The Comet Assay: Mechanisms and Technical Considerations. Mutation Research, 363, 89-96. http://dx.doi.org/10.1016/0921-8777(95)00063-1

[15] Schapoval, E.E.S., Silveira, S.M., Miranda, M.L., Alice, C.B. and Henriques, A.T. (1994) Evaluation of Some Pharmacological Activities of Eugenia uniflora L. Journal of Ethnopharmacology, 44, 137-142. http://dx.doi.org/10.1016/0378-8741(94)01178-8

[16] König, M., Scholz, E., Hartmann, R., Lehmann, W. and Rimpler, H. (1994) Ellagitannins and Complex Tannins from Quercus petraea Bark. Journal of Natural Products, 57, 1411-1415. http://dx.doi.org/10.1021/np50112a010

[17] Duke, J.A. (2005) Chemicals and Their Biological Activities in: Capsicum Annuum L. Dr. Duke’s Phytochemical and Ethnobotanical Databases. USDA-ARS-NGRL, Beltsville Agricultural Research Center, Beltsville. http://www.ars-grin.gov/cgi-bin/duke/farmacy2.pl

[18] Ramírez, R.O. and Roa, C.C. (2003) The Gastroprotective Effect of Tanninsextracted from Duhat (Syzygium cumini Skeels) Bark on HCl/Etanolinduced Gastric Mucosal Injury in Sprague-Dawley Rats. Clinical Hemorheology and Microcirculation, 29, 253-261.

[19] Stehagen, E., Abrahamsan, S. and McLafferty, F.W. (1974) Registry of Mass Spectral Data, Vol. 1. A Wiley Interscience Publication, John Wiley \& Sons, New York, London, 1-826.

[20] Haslam, E. (1996) Natural Polyphenols (Vegetable Tannins) as Drugs: Possible Modes of Action. Journal of Natural Products, 59, 205-215. http://dx.doi.org/10.1021/np960040+

[21] Fernández, O., Capdevila, J.Z., Dalla, G. and Melchor, G. (2002) Efficacy of Rhizophora mangle Aqueous Bark Extract in the Healing of Open Surgical Wounds. Fitoterapia, 73, 564-568. http://dx.doi.org/10.1016/S0367-326X(02)00229-0

[22] Aguwa, C.N. and Nwako, S.O. (1988) Preliminary Studies of the Root Extracts of Nauclea latifolia Smith, for AntiUlcer Properties. Nigerian Journal of Pharmaceutical Sciences, 4, 16-23.

[23] Nwafor, P.A., Effraim, K.D. and Jacks, T.W. (1996) Gastroprotective Effects of Aqueous Extract of Khaya senegalensis Bark on Indomethacin Induced Ulceration in Rats. West African Journal of Pharmacology and Drug Research, 12, 46-50.

[24] Nwafor, P.A., Okwuasaba, F.K. and Binda, L.G. (2000) Antidiarrhoeal and Antiulcerogenic Effects of Methanolic Extract of Asparagus pubescensroot in Rats. Journal of Ethnopharmacology, 72, 421-427. http://dx.doi.org/10.1016/S0378-8741(00)00261-0

[25] Al-Rehaily, A.J., Al-Howiriny, T.A., Al-Sohaibani, M.O. and Rafatullah, S. (2002) Gastroprotective Effects of “Amla” Emblica officinalis on in Vivo Test Models in Rats. Phytomedicine, 9, 515-522. http://dx.doi.org/10.1078/09447110260573146

[26] Tsuyama, Y., Uchida, T. and Goto, T.J. (1992) Analysis of Underivatized C12 to C18 Fatty Acids by Reversed Phase 
Ion-Pair-High Performance Liquid Chromatography with Conductivity Detection. Journal of Chromatography, 596, 181-184. http://dx.doi.org/10.1016/0021-9673(92)85005-E

[27] Jayaraj, A.P., Tovey, F.I. and Hobsley, M. (2003) Duodenal Ulcer Prevalence: Research into the Nature of Possible Protective Dietary Lipids. Phytotherapy Research, 17, 391-398. http://dx.doi.org/10.1002/ptr.1310

[28] Hobsley, M. and Tovey, F.I. (2001) Helicobacter pylori: The Primary Cause of Duodenal Ulceration or a Secondary Infection? World Journal of Gastroenterology, 7, 149-150.

[29] Meshkatal-Sadat, M.H. and Parekh, H.H. (1990) Chemical Investigations of the Flowers of Moltkia caerulea. PlantaMedica, 56, 556 -557. http://dx.doi.org/10.1055/s-2006-961140

[30] Cancino, L., Leiva, A., Garrido, G., Cossio, A. and Prieto, E. (2003) Vimang: Los efectos antigenotóxico y modulador de las enzimas glutatión peroxidasa y glutatión-S-transferasa. Revista Cubana de Investigaciones Biomédicas, 20, 4853.

[31] Remigio, A. (2002) Evaluación genotóxica de seis extractos de plantas medicinales, mediante ensayos in vivo en ratones [Tesis de Maestría]. Facultad de Farmacia y Alimentos, Universidad de La Habana, Ciudad de La Habana.

[32] Labieniec, M. and Gabryelak, T. (2003) Effects of Tannins on Chinese Hamster Cell Line B14. Mutation Research, 39, 127-135. http://dx.doi.org/10.1016/S1383-5718(03)00161-X

[33] Schmid, W. (1976) The Micronucleus Test for Cytogenetic Analysis. Chemical Mutagens, 4, 31.

[34] Wyrobek, A. and Bruce, W. (1975) Chemical Induction of Sperm Abnormalities in Mice. Proceedings of the National Academy of Sciences of the United States of America, 72, 4425-4429. http://dx.doi.org/10.1073/pnas.72.11.4425

[35] González, E., Iglesias, I., Carretero, E. and Villar, A. (2000) Gastric Cytoprotection of Bolivian Medicinal Plants. Journal of Ethnopharmacology, 70, 329-333. http://dx.doi.org/10.1016/S0378-8741(99)00183-X

[36] Nair, C.K.K. and Salvi, V.P. (2008) Protection of DNA from Gamma-Radiation Induced Strand Breaks by Epicatechin. Mutation Research, 650, 48-54. http://dx.doi.org/10.1016/j.mrgentox.2007.10.001

[37] Bustamante, S.E. (2003) Absorción de fármacos. Apuntes docentes.

[38] Carbonaro, M., Grant, G. and Pusztai, A. (2001) Evaluation of Polyphenol Bioavailability in Rat Small Intestine. European Journal of Nutrition, 56, 269-316. http://dx.doi.org/10.1007/s003940170020

[39] Ross, J.A. and Kasum, C.M. (2002) Dietary Flavonoids: Bioavalability, Metabolic Effects, and Safety. Annual Review of Nutrition, 56, 269-316.

[40] Gee, J.M. and Jonson, I.T. (2001) Polyphenolic Compunds: Interactions with the Gut and Implications for Human Health. Current Medicinal Chemistry, 56, 269-316.

[41] Manach, C., Scalbert, A., Morand, C. and Jiménez, L. (2004) Polyphenols: Food Sources and Bioavailability. American Journal of Clinical Nutrition, 56, 269-316.

[42] Spencer, J.P., Schroeter, H., Crossthwaithe, A.J., Kuhnle, G., Williams, R.J. and Rice-Evans, C. (2001) Contrasting Influences of Glucuronidation and $O$-Methylation of Epicatechin on Hydrogen Peroxide-Induced Cell Death in Neurons and Fibroblasts. Free Radical Biology \& Medicine, 31, 1139-1146. http://dx.doi.org/10.1016/S0891-5849(01)00704-3

[43] Scalbert, A., Déprez, S., Mila, I., Albrecht, A.M., Huneau, J.F. and Rabot, S. (2000) Proanthocyanidins and Human Health: Systematic Effects and Local Effects in the Gut. Biofactors, 13, 115-120.

[44] Ezaki, N., Kato, M., Takizawa, N., Morimoto, S., Nonaka, G.I., and Nishioka, I. (1985) Pharmacological Studies on Linderae umbellatae Ramus. IV. Effects of Condensed Tannin Related Compounds on Peptic Activity and Stress-Induced Gastric Lesions in Mice. Planta Medica, 52, 34-38. http://dx.doi.org/10.1055/s-2007-969386

[45] Hung, C.R. and Lee, C.H. (1991) Protective Effect of Cimetidine on Tannic Acid—Induced Gastric Damage in Rats. Journal of Pharmacy and Pharmacology, 56, 269-316. http://dx.doi.org/10.1111/j.2042-7158.1991.tb03536.x

[46] Tebid, K., Besancon, P. and Rovanet, J.M. (1996) Effects of Dietary Grape Seed Tannins on Rat Cecal Fermentation and Colonic Bacterial Enzymes. Nutrition Research, 16, 105-110. http://dx.doi.org/10.1016/0271-5317(95)02064-0 